\title{
Women's Experience of Midwifery Support during Pregnancy - A Step in the Validation of Scale
}

\author{
Mrs. Vimala ${ }^{1}$, Ms. S Monisha ${ }^{2}$, Ms. Nirmala Sharma ${ }^{2}$, Ms. M Padmavathi ${ }^{2}$, Ms. Princy Beula ${ }^{2}$ \\ ${ }^{1}$ Department of Community Health Nursing, Saveetha College of Nursing, SIMATS, Chennai, India \\ ${ }^{2}$ B.sc (Nursing) IV year, Saveetha College of Nursing, SIMATS, Chennai, India
}

\begin{abstract}
DOI: $10.36348 /$ sijog.2020.v03i01.006
| Received: 20.01.2020 | Accepted: 27.01.2020 | Published: 30.01.2020

*Corresponding author: Mrs. Vimala
\end{abstract}

Abstract

Pregnancy is the time in which a foetus develops inside a woman's womb or uterus which usually last about 40 weeks or just over 9 months from the last menstrual period to delivery. The incidence of pregnancies in India is 48.1 million pregnancies, a rate of 144-7 pregnancies per 1000 women aged 15-49 years, and a rate of 70.1 unintended pregnancies per 1000 women aged 15-49 years. Abortions account for one third of all pregnancies and nearly half of pregnancies were unintended. Hence the present study to assess the Women's experience of midwifery support during pregnancy - A step in the Validation of scale. 100 samples who met the inclusion criteria were selected by using a purposive sampling technique. Based on the objectives of the study and review of literature, interview schedule to assess the midwifery support was prepared. It had four areas of midwifery support. The data were analyzed by using descriptive and inferential statistics. The findings of the study revealed that according to the area of midwifery support, the mean percentage score of informational support was $89.29 \%$, followed by financial support of $87.5 \%$, social support of $62.5 \%$ and emotional support of $58.33 \%$. Hence in the area of emotional support the women received average level of support.

Keywords: Women, Midwifery support, Pregnancy, Validation scale.

Copyright @ 2020: This is an open-access article distributed under the terms of the Creative Commons Attribution license which permits unrestricted use, distribution, and reproduction in any medium for non-commercial use (NonCommercial, or CC-BY-NC) provided the original author and source are credited.

\section{INTRODUCTION}

Pregnancy is the period in which a foetus develops inside a woman's womb or uterus which usually last about 40 weeks or just over 9 months from the last menstrual period to delivery. Childbirth may be the most powerful life experience the women undergo. With a midwife's full support, the women can tap into enormous reserves of strength during the birth process and learn that she is capable of so much more than she realized- a valuable discovery as she become a mother [1].

The incidence of pregnancies in India is 48.1 million pregnancies, a rate of 144-7 pregnancies per 1000 women aged 15-49 years, and a rate of 70.1 unintended pregnancies per 1000 women aged 15-49 years. Abortions account for one third of all pregnancies and nearly half of pregnancies were unintended [2]. The blueprint for a healthy life is largely determined by events which take place in the uterus before we are even born. The relationship between a mother and her baby is quite literally, therefore, a partnership for life. One of the most fascinating experiences a woman can go through is pregnancy. A new life is growing inside you, breathing the air that you breathe and drawing nutrition from the food you eat. But there are many more surprising and weird things happening during pregnancy and the subsequent delivery that even experienced mothers are not aware of [3].

There is about 303000 women died from pregnancy related causes, 2.7 million babies died during the first 28 days of life and 2.6 million babies were stillborn. Many primary health centres and hospitals in both rural and urban area have been established to take care of the pregnant women [4].

Although most women enjoy a trouble free pregnancy and delivery, some women may experience complications, such as miscarriage, preterm labour, high blood pressure, poor foetal growth etc. And also 
they often struggled to accept they were experiencing a normal pregnancy because they felt so bad physically. Coping with nausea was more difficult when women had older children, experienced a lack of support, or when they had demanding or inflexible jobs. Some partners helped by providing practical support but no one person can give all the needs that's why women need midwifery support during pregnancy [5].

Midwifery is the health science and health profession that deals with pregnancy. A 2013 Cochrane review concluded that "most women should be offered midwifery-led continuity models of care and women should be encouraged to ask for this option although caution should be exercised in applying this advice to women with substantial medical or obstetric complications [6]. The review found that midwifery led care was associated with a reduction in the use of epidurals, with fewer episiotomies or instrumental births, and a decreased risk of losing the baby before 24 weeks gestation. However midwifery -led care was also associated with a longer mean length of labour as measured in hours. The role of midwifery is not only to care after the health of the pregnant woman, a midwife can give precious information on the social rights of the working woman during pregnancy and lactation, and can give personal attention to the woman and the couple. She can help to diminish the anxiety which is often present during pregnancy. It is somewhat different from care as well as different from social support. It can be emotional support creating a sense of belonging and security, encouraging or offering reassurances about competence in actual situations, offering practical help in actual situations [7]. WHO has issued a new series of recommendations to improve quality of antenatal care in order to give women a positive pregnancy experience and to reduce the risk of stillbirths and pregnancy complications. Despite of this many women experiences lack of midwifery support during pregnancy [8]. "If women are to use antenatal care services and come back when it is time to have their baby, they must receive good quality care throughout their pregnancy," says Dr. Ian Askew, Director of Reproductive Health and Research, WHO. "Pregnancy should be a positive experience for all women and they should receive care that respects their dignity. No one wants to be humiliated or beaten by health staff (like I was), especially when we go for delivery. We expect love and care. We are helpless there. I think it is important to raise the staff's awareness. I don't know how to do that, but this would be the only way of changing them. I never wished to tell this story to anyone else, but today I told you everything because I want to help others to not have to face unpleasant situations. (Experts from author's interview with a Tamil woman) The woman's statement "I wanted her to be there for me, but not for the hospital" - critical of lack of support she received from her midwife. The NMC's Code of professional conduct stresses advocacy on behalf of women but her contract requires her to comply with hospital policies. If woman's choices challenge hospital policy, then the midwife is caught between allegiances. This illustrates a growing ambivalence in many midwives 'understanding of their role [9].

\section{METHODS AND MATERIALS}

The Research approach used in this study was quantitative approach by using descriptive research design. After getting formal permission from the principal of Saveetha College of nursing and from head of the obstetrics and gynaecology department at Thiruvallur Government Headquarters. 100 samples who met the inclusion criteria were selected by using a purposive sampling technique. Based on the objectives of the study and review of literature, interview schedule to assess the midwifery support was prepared. It had four areas of midwifery support - emotional, informational, social and financial. The tool was validated by experts from the field of obstetrics and Gynaecology, Medicine, Maternal and Child Health Nursing and paediatric Nursing. The employees who consented for willing to participate were explained about the purpose and benefits about the study. Demographical variables were collected by using self structured multiple choice questionnaires followed by using Validation Scale. The data were analyzed by using descriptive and inferential statistics.

\section{RESULTS}

According to the area of midwifery support, the mean percentage score of informational support was $89.29 \%$, followed by financial support of $87.5 \%$, social support of $62.5 \%$ and emotional support of $58.33 \%$. Hence in the area of emotional support the women received average level of support. And out of 100 samples $25(55 \%)$ had good outcome of maternal health, $45(45 \%)$ had average maternal health and $30(30 \%)$ had below average maternal health output. The study reveals that there is a significant variable in demographic variables such as, education, occupation, type of family, place of residence, where as non significant shows in age, religion, family income and no of child.

Table 1: Determine the outcome of midwifery support received by the women

\begin{tabular}{|l|l|l|l|}
\hline S. NO & Outcome of midwifery support & Frequency & Percentage \\
\hline 1. & Good & 25 & $25 \%$ \\
\hline 2. & Average & 45 & $45 \%$ \\
\hline 3. & Below average & 30 & $30 \%$ \\
\hline
\end{tabular}




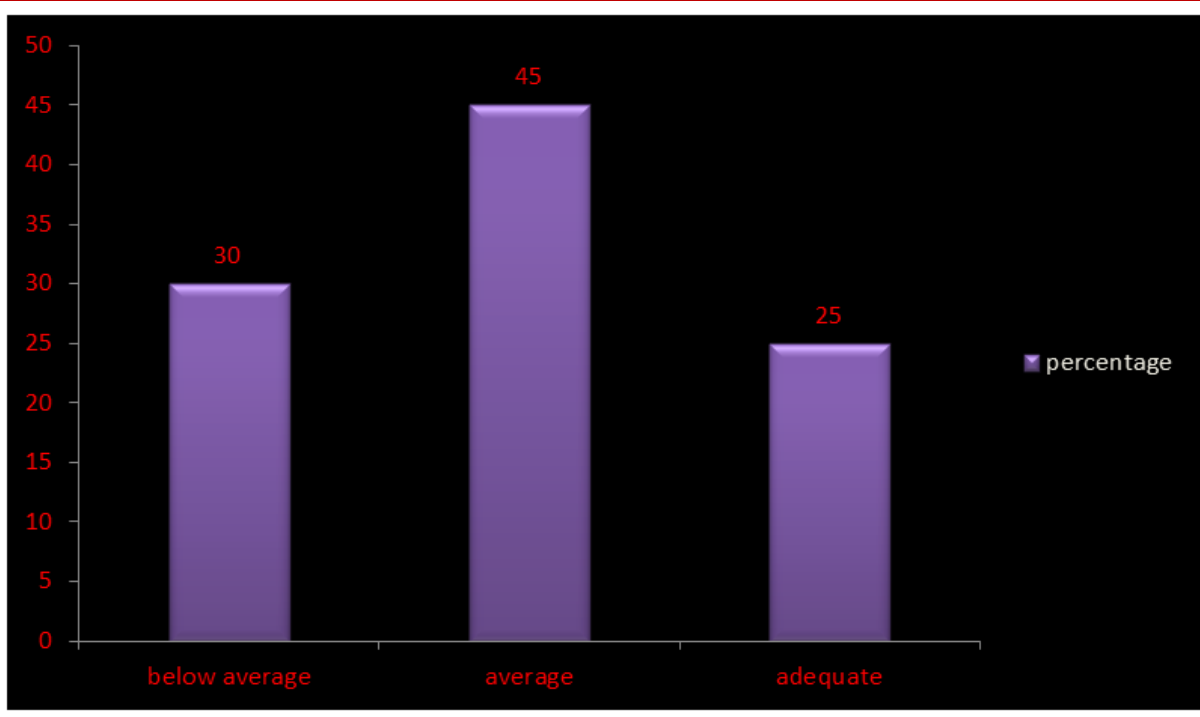

Fig-1

\section{DISCUSSION}

Midwifery support is the health science and health profession that deals with pregnancy, childbirth and the postpartum period in addition to the sexual and reproductive health of women throughout their lives. Midwives are qualified to assist with a normal vaginal delivery while more complicated deliveries are handled by a health care provider who has had further training.

The present study was supported by Andrea solnesmiltenburg, et al., [13] who conducted a study on antenatal care is essential to improve maternal and newborn health and wellbeing. This study took in Tanzania as a part of an exploratory and baseline study for the Women Centered Care Project, the study design was purposive sampling was used to select health facilities and villages in 9 of 18 wards of the districts, based on population size. The result shows that inadequate resources contribute to poor quality of ANC and many routine ANC services seem to be neglected.

The findings of the study revealed that according to the area of midwifery support, the mean percentage score of informational support was $89.29 \%$, followed by financial support of $87.5 \%$, social support of $62.5 \%$ and emotional support of $58.33 \%$. Hence in the area of emotional support the women received average level of support.

The present study was supported by Larsson $\mathrm{B}$, et al., who conducted a study to explore women's experiences of midwife counselling for childbirth fear. A qualitative interview study using thematic analysis. 27 women assessed for childbirth fear who had received counselling during pregnancy. The midwife counselling brought positive feelings and improved confidence in birth was identified. This consisted of four themes describing the importance of the midwife and a mutual and strengthening dialogue during pregnancy. The positive birth experience strengthens the self- confidence for a future birth and the childbirth fear was described as reduced [10].

The findings of the study revealed that out of 100 samples $25(55 \%)$ had good outcome of maternal health, 45(45\%) had average maternal health and 30 (30 $\%)$ had below average maternal health output.

The present study was supported by Elke Mattern, et al., the study conducted in Germany, comprehensive research to more fully understand women's needs in pregnancy, labour, birth and the postpartum period until weaning is lacking. The study explores pregnant women's and mother's experiences, needs and wishes regarding systemic aspect of midwifery care.50 women participated in 10 focus groups in 5 sales of Germany. The result shows that three themes were identified: (a) knowledge or lack of awareness of midwifery care b) availability of and access to midwife and c) midwife care in the healthcare system [11].

The study reveals that there is a significant variable in demographic variables such as, education, occupation, type of family, place of residence, whereas non -significant shows in age, religion, family income and no of child.

The present study was supported by Stina Lou, et al., conducted a study on a dominant women context for pregnant women in the western world is medical technological such as ultrasound and screening. The objective of the study was to understand the core experiences and perspective of mothers who participated in GPC sessions during their pregnancy period. A qualitative research approach was used to understand the experiences of women receiving GPC. A total 21 in depth were conducted in this study targeting pregnant women who attend all GPC session. Face to face interviews were conducted by trained and 
experienced interviewers. The result shows that the mothers appreciated to receiving pregnancy care in group [12].

\section{CONCLUSIONS AND RECOMMENCATIONS}

This chapter deals with the implication of the study in the field of nursing, limitations, suggestions and recommendations for the research. On the whole, conducting this study was a rich learning experience for the investigator.

Conflict of Interest: There is no conflict during the study.

\section{REFERENCE}

1. Office on Women's Health. (2010). About Pregnancy. Retrieved May 20, 2016, from http://womenshealth.gov/pregnancy/you-arepregnant/stages-of-pregnancy.html

2. https://www.nct.org.uk/pregnancy/who-will-carefor-you-during-pregnancy/what-midwife.

3. The lancet Global Health, The incidence of abortion and unintended pregnancy in India, 6(1): January 2018.

4. Stefan Kane, pregnancy research, [online], https://www.thewomens.org.au/research/researchcentres/womens-pregnancy-research-centre.

5. World Health organization, Maternal mortality,[online], https://www.who.int/newsroom/fact-sheets/detail/maternal-mortality. [accessed 2017].

6. Definition of Midwifery, Encyclopaedia Britannica, retrieved 5 Feb 2017[https://en.wikipedia.org/wiki/Midwifery]
7. Who recommendations on antenatal care for a positive pregnancy experience, new guidelinesNov 2016.

8. World Health organization, Pregnant, https://www.who.int/news-room/detail/07-112016-pregnant-women-must-be-able-to-accessthe-right-care.

9. Denis Walsh, the role of the Midwife, Time for a review, 10(7); july 2017, https://www.researchgate.net/publication/6183661

10. Larsson, B. (2019). Reported that the mean percentage score of informational support was $80.29 \%$, followed by financial support of $82.5 \%$, social support of $60.5 \%$ and emotional support of $50.33 \%$. Hence in the area of emotional support the women received average level of support.

11. Elke Mattern. (2016). Reported that out of 100 samples $20(55 \%)$ had good outcome of maternal health, 40(45\%) had average maternal health and $40(30 \%)$ had below average maternal health output.

12. Stina, L. (2017). Reported that that there is a significant variable in demographic variables such as, age, occupation, type of family, place of residence, whereas non -significant shows in education, religion, family income and no of child.

13. Solnes Miltenburg, A., van Pelt, S., Meguid, T., \& Sundby, J. (2018). Disrespect and abuse in maternity care: individual consequences of structural violence. Reproductive health matters, 26(53), 88-106. 